\title{
Indian Ocean Rim Association for Regional Cooperation (IOR-ARC): Impact on Australia's Trade
}

\author{
K.P. Kalirajan \\ Australia South Asia Research Centre, Australian National University
}

\begin{abstract}
Estimates of the gravity equation explaining trade flows between Australia and other member countries of IOR-ARC indicate that the signal of market-driven economic cooperation within IOR-ARC is strong due to the presence of APEC members. The intra-industry trade analysis between Australia and other IOR-ARC countries further confirms that the market-driven economic cooperation between them is feasible.

- JEL Classifications: F15 and F14.

- Key Words: APEC, 10R-ARC, Varying Coefficients Graviting Equation, Intra-Industry Trade.
\end{abstract}

\section{Introduction}

Economic integration among a group of countries occurs in several forms such as the preferential trade arrangements, establishing free trade areas, and naturally without any particular trading arrangements. It has been well established in the literature that the Asia Pacific Economic Cooperation (APEC) is a good example of an integration that is natural and market-driven without any particular trading arrangements and strengthened by trade and investment liberalisation pursued by several countries in the region. Unlike the European Economic Community (EEC), APEC is more a functional integration rather than a geographical integration. APEC was established at a meeting of Foreign and Economic

\footnotetext{
*Corresponding Address: K.P. Kalirajan, Executive Director, ASARC/RSPAS, The Australian National University, Canberra, ACT 0200, Australia, Fax: +61-2-6249 3700, Email: Kali.Kalirajan@ anu.edu.au, Phone: +61-2-62493096

The author acknowledges with thanks an anonymous referee of this Journal for the useful suggestions. (C)2000-Institute for International Economics, Sejong Institution. All rights reserved.
} 
Ministers in 1989 for the countries and territories washed by the Pacific Ocean, and with the aim of sustaining the growth and development of the region for the common good of its people; to contribute to the growth and development of the world economy; to enhance the positive gains both for the region and the world economy; to enhance the positive gains both for the region and the world economy resulting from increasing economic independence; to develop and strengthen the open mutual trading system; and to reduce the barriers to trade in goods, services and investment among participating economies.

The ministers have created ten working groups to advance practical cooperation among the members in the following areas: trade and investment data, trade promotion, investment and technology transfer, human resources development, regional energy cooperation, marine resource conservation, telecommunications, transportation, tourism and fisheries. In addition, there is an ad hoc group on economic trends and issues, and an informal group on regional trade liberalisation.

The establishment of the Secretariat in 1993 has transformed APEC from an informal dialogue group to a formal institution comprising all the major economies of the Asia-Pacific region. The Secretariat provides APEC with the institutional base for more effective cooperation on a wide range of practical projects and for cooperation with other regional institutions.

APEC has emerged as a central force for regional cooperation and trade liberalisation in the Asia-Pacific region. It provides a forum for discussion on a broad range of economic issues of importance to the region. It has also established a strong basis for policy development. Ministerial meetings have been held on an annual basis since the first meeting in 1989. There are also regular meetings of senior officials three or four times per annum.

Recently, the recognition of the successful functioning of APEC has encouraged a major economic cooperation initiative within the Indian Ocean Rim. It is also worth noting that some of the APEC countries are also Indian Ocean Rim countries. Given this characteristic of APEC economic integration, the important question addressed in this paper is whether such market-driven natural economic cooperation is feasible within the 14 member countries of the recently formed Indian Ocean Rim-Association for Regional Cooperation (IOR-ARC Receutly, Bangladesh, Irah, Seychelles, Thailand and United Arab Emirates have been admitted into 10R-ARC). These fourteen countries are: Australia, India, Indonesia, Kenya, Madagascar, Malaysia, Mauritius, Mozambique, Oman, Republic of South Africa, Singapore, Sri Lanka, Tanzania and Yemen (see, Shand 
and Kalirajan, 1997). It is argued that robust and rapid economic integration depends upon whether intra-regional market forces are in fact dynamic and upon the ways in which attempts to stimulate the process of integration are designed and implemented. The first question is addressed in this paper from the viewpoint of Australias trade relationship with the other IOR-ARC countries. In this paper, we are neither concerned with whether there is any welfare improvement for Australia or for any other countries to be in IOR-ARC, nor suggesting the creation of IORARC trade bloc.

The objective of this paper is to address the question whether natural economic integration in the lines of APEC is feasible with IOR-ARC by examining the main trends and patterns of trade flows between member countries with emphasis on Australias relationship with member countries. Analysis in this paper is based on SITC 0-9 at 3-digit levels. Data are taken from UN Trade data from 1985 to 1995, available in the International Economic Data Bank (IEDB) at The Australian National University.

This paper is organised in two sections. In the first, trends and components of overall trade linkages within the 14 member countries from 1985 to 1995 are discussed to examine the prospects for market-driven economic cooperation. The second section brings together the conclusions.

\section{Trade Linkages within IOR-ARC Countries}

Two basic approaches are used in the literature to discuss trade linkages between countries ${ }^{1}$ : (1) The first analyses factors influencing trade between countries by examining the patterns of trade between countries over time, given the total trade, and (2) The second identifies factors that determine the size of trade flows and analyses why the size of international trade flows differs between different pairs of countries. Nevertheless, the main focus in both approaches is to work out the impact of resistance to bilateral trade flows with respect to some benchmark level of trade, which is usually described as the potential trade between countries $^{2}$.

IOR-ARC countries contributed about 10 per cent of world exports and about

\footnotetext{
${ }^{1}$ For a brief but comprehensive review see, Yamazawa (1970), and Drysdale and Garnaut (1982).

${ }^{2}$ Drawing on Kalirajan (1998), potential trade can simply be defined as the maximum possible trade that can occur between countries, given the determinants, and this potential may constantly be changing as countries either increase or decrease the impediments to trade.
} 
10 per cent of world imports during the last decade. Although the share of IORARC countries in world trade remained more or less constant at the same level, its contribution to trade in different regions in the world varied. Bilateral trade relationships within IOR-ARC described in terms of intensity indices, help to identify how intensively the member countries are trading with each other. The intensity of trade index is defined as the share of one country's trade with another country, divided by the other country's share of world trade. A value of unity implies that the bilateral relationship between two countries is as important as their trade with the rest of the world. A value greater (less) than one indicates a high (low) intensity in bilateral trading relationship.

The trade intensity index $\left(I_{i j}\right)=\left(\frac{X_{i j}}{X_{i}}\right) /\left(\frac{M_{i}}{M_{w}-M_{j}}\right)$

where $X_{i j}$ is exports of country $i$ to country $j$

$X_{i}$ is total exports of country $i$

$M_{w}$ is total world imports

$M_{i}$ and $M_{j}$ are total imports of country $i$ and $j$, respectively.

Intensity of trade between countries diverges from unity for several reasons which can be classified into two categories-objective resistance and subjective resistance (Garnaut, 1972). For example, in the context of objective resistance, intensity of trade is likely to be high between a combination of industrial exporter and a primary product exporter where strong complementarity exists in their structure of comparative advantage. On the other hand, intensity will be low between either two industrial exporters or two primary products exporters. In the context of subjective resistance, discriminatory commercial policies, flow of capital and economic aid from the developed to developing economies are some of the important factors that influence the intensity index (Yamazawa, 1970). While countries have only limited control over objective resistance, they can eradicate subjective resistance completely by cooperating with each other either bilaterally or multilaterally. Regional cooperation arrangements such as the IORARC can facilitate the removal of the latter resistance through dialogues and discussions.

Trade intensity indices were calculated for trade within the 14 IOR-ARC countries from 1985 to 1995 . The results (which will be given by the author on request) indicate that a majority of member countries are trading more intensively 
among themselves than on the average. The intensity increased in the early 1990s, which is as expected because the reform measures undertaken in several IORARC countries in the 1990 s have made a significant impact on trade linkages within the group. However, some countries, particularly Mozambique, Oman, Tanzania, and Yemen are not actively trading with other member countries. Detailed research to determine whether subjective or objective resistances have caused such a trade pattern is warranted.

Given the existing resistance between Australia and its trading partners in IORARC, this paper uses the gravity model introduced by Tinbergen (1962) to identify the determinants of trade flows between them. As discussed in Anderson (1979), the gravity model is the most successful empirical trade flow equation that usually produces a good fit. This model provides an empirically tractable general equilibrium framework for bilateral trade flow analysis. The basic formulation of the gravity equation has income and population of the trading partners and the distance between them as the independent variables, hypothesising that the trade flows between two countries are mainly determined by these factors ${ }^{3}$. The prices of commodities are not included as a determinant, as this approach studies equilibrium trade flow that result from interaction of supply and demand with prices as an endogenous variable.

Gravity equations are specified in a number of ways. Treatment of resistance factors varies widely in different specifications. Linnemann (1966) used distance and preference area variables to represent resistance. Geraci and Prewo (1977) argued that distance variables did not represent transport cost fully since this cost might be influenced by several other factors like value, weight, bulk and mode of transportation ${ }^{4}$. They used both quantitative and qualitative components of the resistance factor in their formulation. The first quantitative component, called the transport cost factor, is the ratio of true c.i.f value to the true f.o.b value. This can be measured in two ways: first, as the ratio of the observed c.i.f. value for $X_{i j}$ (measured at $j$ ) to the observed f.o.b. value for $X_{j}$ (measured at $i$ ). Second, the transport cost may be specified as a function of the geographical distance between

\footnotetext{
${ }^{3}$ The origin of the gravity model is not, however, a hypothetical deductive development but an intuitive approximation. Economists are not in consensus about the theoretical formulation and the functional form of the gravity equation. Empirical success, however, encouraged research for finding its theoretical foundation. Anderson (1979) provided a theoretical explanation for the equation using the properties of pure expenditure systems with the hypothesis of identical homothetic preferences across regions and products differentiated by country of origin (Armington assumption).

${ }^{4}$ Recently, Panagariya (1998) argues that transport costs do not justify regiona preferential arrangements.
} 
commercial centres of $i$ and $j\left(D_{i j}\right)$ and the average unit value of exports from $i$ $\left(V_{j}\right)$. Again the distance varies according to the mode of transportation which necessitates adjustment with use of some weights. The second quantitative component is the average nominal tariff of country $j\left(Z_{j}\right)$. Geraci and Prewo used three qualitative variables to represent the resistance factor. These are preference area, common language and neighbourhood. Brada and Mendez (1983) used the gravity equation to estimate the integration-augmented effect on intermember trade. They used dummies for the time variable to capture the secular change in trade flows independent of the integration effect. To find out the probable economic reasons for failure or success of the individual schemes, Brada and Mendez modified this equation further by introducing dummy variables for integration-per capita income interaction and integration-distance interaction.

Aitken (1973) used the gravity equation to estimate the integration effect of EEC and EFTA on European trade. He used cross section data for each year during pre and post-union integration periods to estimate gross trade creation (GTC) as defined by Balassa (1965), and trade diversion. Balassa defined gross trade creation as the total increase in trade among the members of the bloc regardless of whether additional trade replaces domestic production or third country exports. He defined external trade creation as the integration induced increase in trade of the bloc with the outside world. External trade creation minus trade diversion yields the net effect of integration.

In estimating a gravity equation, Krugman (1991) examined whether there is resistance in North American and European trade by directly testing for intraregional bias in trade. He concluded that there has been intra-regional bias in trade in North America and Europe. Frankel (1993) estimated a pooled cross-country gravity equation using data from more than sixty countries to determine the existence of intra-regional bias in trade and found evidence against openness not only in North American and European trade, but also in East Asian trade. In contrast to earlier studies, Dhar and Panagariya (1996) estimated both countryspecific and pooled cross-country gravity equations to examine the question of openness in North America, Europe and East Asia. An important finding of their study is that a country-specific gravity equation can explain trade flows between countries better than a cross-country gravity equation because the latter masks large differences across countries. In this paper, following Kalirajan (1998), the Dhar and Panagariya's approach of estimating country-specific gravity equations is used for Australias trade within IOR-ARC. 
However, the modelling of country-specific gravity equations and estimation procedures followed in this paper differ from those of Dhar and Panagariya. In their model specification, partner countries of equal distance from the reporter country will have the same effect on trade flows which is not realistic. For example, New Zealand and Indonesia are more or less equal in distance from Australia, but the trade flows between these countries and Australia are not the same due to various policy factors. Also, as Deardorff (1997) has argued pairs of countries that are neighbours but away from other trading partners would trade more with each other than similar pairs, which are close to other trading partners. The implication is that the coefficient of distance cannot be fixed, but should vary across countries. Similarly, same levels of GDP need not lead to same amount of trade flow due to different factors such as the structure of the economies. One way of correcting this limitation is to include the policy and other related variables in the model in an additive fashion to analyse their effects on trade flows. However, if trading partners actually take these policies and other related variables into account in their decisions on trading, these variables would enter the gravity model, not in an additive manner, but as determinants of the parameters in the model. Thus, as suggested by Kalirajan (1998) a gravity model with varying coefficients would explain trade flows between countries better than a gravity model with fixed coefficients.

Assuming Cobb-Douglas technology, the varying coefficient gravity equation can be written as:

$$
\begin{aligned}
\ln T_{j t}^{i}= & \beta_{1 j t}^{i}+\beta_{2 j}^{i} \ln \left(d i s \tan c e_{j}^{i}\right)+\beta_{3 j t}^{i} \ln \left(G D P_{t}^{i}\right)+\beta_{4 j t}^{i} \ln \left(G D P_{j t}\right) \\
& +\beta_{5 j t}^{i} \ln \left(P C G D P_{j t}\right)+\beta_{6 j t} D_{j t}+\varepsilon \\
& j=1,2, \ldots n ; i \neq j \text { and } t=1990, . .1994 .
\end{aligned}
$$

where $T$ refers to total annual trade measured in US dollars; the superscript $i$ denotes the reporter country, $j$ the partner country; $\operatorname{distan} c e_{j}^{i}$ denotes the straightline distance between major ports of entry of countries $i$ and $j$; $G D P^{i}{ }_{t}$ refers to total gross domestic product of country $i$ in period $t$ in US dollar; GDP $P_{j t}$ and $P C G D P_{j t}$ refer to the total and per capita gross domestic product of country $j$ in period $t$ in US dollars; $D_{j t}$ is a dummy variable which takes the value 1 , if the jth partner country and the ith reporter country belong to the APEC group, otherwise 0 , and $\varepsilon$ is the statistical error term with normal properties. Since intercepts and slope coefficients vary across countries, we can write: 


$$
\begin{aligned}
& \beta_{k j t}=\bar{\beta}_{k}+u_{j}+v_{t} \\
& \beta_{l i}=\bar{\beta}_{1}+u_{j}+v_{t}
\end{aligned}
$$

where $\bar{\beta}_{k}$ is the mean response coefficient of total trade with respect to the $k^{\text {th }}$ factor and $u_{j}$, is the deviation of the $j^{\text {th }}$ countrys coefficient of trade with respect to the $k^{\text {th }}$ factor from the mean response coefficient $\bar{\beta}_{k}$ and $v_{t}$, is the deviation in the $t^{\text {th }}$ period. These deviations occur due to specific factors (or bias) that govern the trade flow between countries $i$ and $j$. Similarly, $u_{\mathrm{j}}$, is the deviation of the $j^{\text {th }}$ countrys constant term from the mean constant term $\bar{\beta}_{1}$ and $v_{t}$ is the deviation in the $t^{\text {th }}$ period. Now, it becomes apparent that the number of coefficients to be estimated is greater than the number of observations. As suggested by Swamy (1970), a method to overcome this problem to estimate the mean response coefficients and the variance co-variance matrix is to treat both $v_{t}$ and $w_{t}$ as random variables. The following assumptions are made:

$$
\begin{aligned}
& E\left(\beta_{k j t}\right)=\bar{\beta}_{k} \quad \operatorname{Var}\left(\beta_{k j t}\right)=\sigma_{k t}^{2}>0 \\
& \text { and } \operatorname{Cov}\left(\beta_{k j}, \beta_{m j}\right)=0 \quad k \neq m
\end{aligned}
$$

These imply that the varying coefficients $\beta_{k j t}$ are independently and identically distributed with fixed mean $\bar{\beta}_{k}$ and variance $\sigma_{k t}^{2}$.

Table 1. Estimates of Stochastic Varying Coefficients Gravity Equation Between Australia and its Trading Partners within IOR-ARC

\begin{tabular}{lccc}
\hline \multirow{2}{*}{ Variables } & \multicolumn{3}{c}{ Coefficient Estimates } \\
\cline { 2 - 4 } & Minimum Value & Maximum Value & Mean Value \\
\hline Constant & 10.8568 & 13.1267 & 12.6552 \\
Distance & $(4.8973)$ & $(6.0024)$ & $(5.9832)$ \\
& -3.7526 & -0.8672 & -2.4505 \\
Australian GDP & $(0.6743)$ & $(0.2321)$ & $(0.5890)$ \\
Reporter GDP & 0.2698 & 0.3826 & 0.3216 \\
& $(0.0443)$ & $(0.0753)$ & $(0.0654)$ \\
Reporter per capita GDP & 0.7045 & 0.8956 & 0.8008 \\
& $(0.0565)$ & $(0.0521)$ & $(0.0433)$ \\
APEC Membership Dummy & 0.2986 & 0.4118 & 0.3998 \\
& $(0.0452)$ & $(0.0528)$ & $(0.0517)$ \\
& 0.7672 & 0.9215 & 0.8952 \\
& $(0.2245)$ & $(0.3018)$ & $(0.2952)$ \\
\hline
\end{tabular}

Note: All the coefficients are significant at least at the 5\% level. 
Combining equations (1) and (2), the ' $n t$ ' observations can be written in matrix format:

$$
T=X \bar{\beta}+w \text { where } w=D_{x} u+Q_{x} v+\varepsilon
$$

Thus, equation (3) is a linear regression with constant coefficients of mean responses and heteroscedastic disturbances. Thus, the random coefficient regression model reduces to a model with fixed coefficients, but with heteroscedastic variances. So, the ordinary least squares (OLS) method yields unbiased but inefficient estimates of mean response coefficients. Since, the elements of the variance co-variance matrix $\Gamma_{w}$ are not known, they have to be estimated. Hildreth and Houck (1968) suggest several methods of estimating the elements of $\Gamma$. In this study, we used the Aitken's generalised least squares (GLS) to estimate $\bar{\beta}$ s by following the arrangements of Swamy (1970). ${ }^{5}$ Now, following Griffiths (1972), the actual country-specific, timespecific and factor-specific response coefficient predictor for the $j^{\text {th }}$ observation for the $k^{\text {th }}$ input in the $t^{\text {th }}$ period, $\beta_{k j t}$, which is the best linear unbiased predictor (BLUP), can be obtained (Kalirajan, 1998).

The above random coefficients country-specific gravity model was estimated for Australia and its trading partners within IOR-ARC using the IEDB trade data from 1985-1995. The iterated GLS estimates of the actual response coefficients, mean response coefficients of factors are given in Table 1. All the mean response coefficients are significant at the 5 per cent level. The signs and magnitudes of these variables are in conformity with theoretical expectations. The range of actual response coefficients show that there are variations in country-specific trade and other related policies that influence the trade flows between Australia and its IORARC trading partners. In other words, the contributions of country-specific factors to total trade flows differ from country to country. The $\mathrm{R}^{2}$ value indicates that about $90 \%$ of total trade flows between Australia and its IOR-ARC trading partners were explained by the five explanatory variables included in the gravity equation.

The coefficient estimate of the variable 'distance' is negative and varies from -0.86 (Indonesia) to -3.72 (Mozambique). As the coefficient of the 'distance' variable can be interpreted to measure the influence of both transport costs and Deardorf's (1997) distance of countries from the center of gravity of global business activity, the implication of the above result is that any increase in

\footnotetext{
${ }^{5}$ This method involves iterative procedures and iterations continue until parametr $\beta$ 's are stabilised. Interested readers are referred to Swamy (1970), and Grfffiths (1972).
} 
transport cost of a country with which Australia's trade intensity is low would reduce the trade flows drastically. $G D P_{j}$ or the partner country GDP has a positive effect on total trade flows with Australia. The estimate of the coefficient varies between 0.55 (Mozambique) and 1.25 (India). GDP of Australia is also positive and varies from 0.45 (Tanzania) and 1.36 (Malaysia). The coefficient of reporter per capita GDP ranges from 0.26 (Tanzania) to 1.28 (Mauritius). The coefficient of APEC membership dummy is positive and significant which implies that trade flows between APEC members within IOR-ARC are at a much higher level than trade flows between Australia and other non-APEC trading countries within IORARC. As Panagariya (1998) has argued, this result cannot be interpreted to mean as a measure of 'trading bloc' as suggested by Frankel et al. (1995). The inference is that market-driven natural economic integration such as in APEC increases trade flows between member countries, and that the potential spill-over effect from these APEC and IOR-ARC member countries (Australia, Indonesia, Malaysia and Singapore) influencing the entire IOR-ARC towards market-driven natural cooperation without any formal preferential trading or regional arrangements is very high. However, similar country-specific gravity equations should be estimated with each member countries of IOR-ARC along with the appropriate regional grouping dummies to gain a clearer picture of integration.

Analysis of intra-industry trade provides another measure to examine the evolution of economic linkages that are market-driven. Verdoorn (1960) in his study of the Benelux Customs Union (BCU) concluded that specialisation and exchanges took place within rather than between different categories of products within BCU. Balassa (1965), Grubel and Lloyd (1975), Krugman (1981), and Tharakan and Kol (1989) in their empirical studies concluded that, under a wide range of circumstances, free international trade would result in a situation where each country would simultaneously produce, export, and import commodities that are identical or very close substitutes in consumption, production and both. Experiences of the existing regional groups suggest that economic grouping of countries with more or less similar endowments will be successful and sustainable because adjustment process following economic reforms, especially, liberalisation of trade policy within the grouping would be less disruptive, if adjustment process took place in the form of intra-industry trade. Fukasaku (1992), in explaining why intra-industry adjustment is less disruptive in newly reforming countries, argues that intra-industry adjustment requires re-allocation of resources mainly within firms in the same industry rather within than firms in different industries. This means that adjustment 
Table 2. Intra-Industry Trade Index: Australia with IOR-ARC Countries

\begin{tabular}{lccc}
\hline \multirow{2}{*}{ Country } & \multicolumn{3}{c}{ Intra-industry trade index (commodity total: SITC 5-8 at 3 digit) } \\
\cline { 2 - 4 } & 1985 & 1990 & 1995 \\
\hline India & 6.25 & 8.89 & 18.28 \\
Indonesia & 4.94 & 9.96 & 21.25 \\
Kenya & 1.71 & 2.66 & 4.82 \\
Madagascar & 0.00 & 0.00 & 1.98 \\
Malaysia & 20.06 & 24.02 & 35.98 \\
Mauritius & 10.88 & 13.09 & 24.05 \\
Mozambique & 0.00 & 0.00 & 0.00 \\
Omen & 0.00 & 4.54 & 5.24 \\
Singapore & 33.14 & 36.26 & 42.04 \\
Tanzania & 0.00 & 0.87 & 1.06 \\
Yemen & 0.00 & 3.86 & 4.56 \\
Sri Lanka & 6.01 & 7.11 & 8.65 \\
South Africa & 27.24 & 28.42 & 29.35 \\
\hline
\end{tabular}

costs in the former case are lower than in the latter. Thus, the prospect for closer economic co-operation among a group of countries can be examined by analysing the status of intra-industry trade within the concerned group of countries ${ }^{6}$.

Our interest in this paper is to examine the variations in the growth of IIT among the IOR-ARC countries with the following two policy-oriented hypotheses, namely, that IIT will be greater when tariffs and non-tariff barriers are low, and when economies are subject to some form of economic integration that are not necessarily formal trading arrangements. It is particularly hypothesised here that due to liberalisation and globalisation, the extent of intra-industry trade among some IOR-ARC countries will increase over time as an indicator of close co-operation in manufacturing activities. Examination of this proposition necessitates calculating the well known Grubel-Lloyd (1975) intra-industry trade index (IITI). Aquino (1978) criticised the Grubel-Lloyd index by saying that the index is a downward-biased measure of IIT in the presence of an imbalanced country's commodities trade. Aquino's suggested correction of the Grubel-Lloyd index was rejected by many researchers (see, for example, Greenaway and Milner, 1981 and Tharakan, 1984). In fact, Aquino adopted Michaley's (1962) index,

\footnotetext{
${ }^{6}$ The level of IIT depends crucially on the level of aggregation. If IIT is measured at a very detailed classification level, there might be very little trade. On the other hand, if IIT is measured at a very high level of aggregation, most trade will be IIT. The standard empirical works have often reported IIT at the 3-digit level of aggregation.
} 
which measures similarities in structures of exports and imports rather than IIT. In the literature, many researchers have effectively used the unadjusted Grubel-Lloyd index to measure IIT (see, for example, Caves, 1981 and Vona, 1991).

The Grubel-Lloyd index is expressed as a ratio of the value of exports, which is matched by imports to the total value of exports and imports of an industry.

$$
\beta_{i j}=\left[1-\left(\sum_{k=1}^{m}\left|X_{k}-M_{k}\right| / \sum_{k=1}^{m}\left(X_{k}+M_{k}\right)\right)\right] \times 100
$$

$\beta_{i j}=100$ indicates that all trade of country $j$ with country $i$ is intra-industry. When $\beta_{i j}=0$, this means that all trade is inter-industry and that there is complete specialisation in trade between two countries. The higher the ratio, the greater is the intra-industry trade and so, close co-operation in manufacturing activities of the countries concerned.

As an example, Table 2 gives IITI between Australia and other IOR-ARC countries and the world. Intra-industry trade between Australia and the World has been increasing over the period of analysis which indicates that Australia's integration with the global economy is becoming stronger. It increased from 20 in 1985 to 40 in 1995. Among the IOR-ARC countries who had the largest share of intra-industry trade with Australia in 1995 in order of magnitude were Singapore (42), Malaysia (36), South Africa (29), Mauritius (24), Indonesia (21) and India (18). The indices have been increasing consistently from 1985 .

The empirical results of our analysis above indicate that the amount of intraindustry trade that is taking place within IOR-ARC is at a low level, but, that intraindustry trade indices between Australia and some countries within IOR-ARC have been increasing recently. The empirical results can partly be explained by the convergence of the factor endowments. When the relative difference in capital stock per head between two countries is greater, then the share of intra-industry trade in total bilateral trade will be smaller. Next, an increase in intra-industry trade occurs when there is a simultaneous growth of economic size or a lowering of transaction costs among trading partners, whether by a relative decrease of prices for transport and communication services or by a removal of policy imposed trade barriers. Therefore, more liberalisation within IOG provides greater opportunities for IIT within the region, which in turn facilitates the formation of, and the sustaining of an IOG.

The above IIT analysis also indicates that economic cooperation such as the 
APEC has facilitated increasing consistently Australia's IIT, particularly manufacturing with its APEC members Singapore, Malaysia and Indonesia. Now, with the IOR-ARC, there is significant potential to improve IIT to bring closer cooperation among its members.

\section{Conclusions}

APEC has been acknowledged as a successful and dynamic economic cooperation mainly governed by market forces without any formal trading or regional arrangements. Recognition of its success in terms of promoting overall economic growth in member countries has recently led to a major initiative towards the creation of regional economic integration within the Indian Ocean Rim. As some of the APEC member countries are also Indian Ocean Rim countries, the questions addressed in this paper are: whether the APEC-style market-driven economic integration is feasible with IOR-ARC and how effective are the trade linkages between Australia and IOR-ARC member countries.

Trade intensity measures indicate that a majority of IOR-ARC member countries are trading with each other intensively recently and the positive trend is encouraging. Estimates of the gravity equation explaining trade flows between Australia and other member countries of IOR-ARC indicate that the signal of market-driven economic cooperation without any formal regional arrangement within IOR-ARC is strong due to the spill-over effect of the presence of APEC members. The intra-industry trade analysis between Australia and other IOR-ARC countries further confirm this result. The conclusion is that the possibility of IORARC growing naturally as like APEC without any particular trading arrangements among the constituent countries is feasible.

Date frist submitted: 14 October 1998; Date finally accepted: 10 April 2000.

\section{References}

Aitken, N.D. (1973), "The Effect of EEC and EFTA on European Trade: A Temporal Cross-Section Analysis," American Economic Review, 63, 881-892.

Anderson, J.E. (1979), "A Theoretical Foundation for the Gravity Equation," American Economic Review, 69, 106-116.

Aquino, A. (1978), "Intra-Industry Trade and Inter-Industry Specialisation as Concurrent Sources of International Trade in Manufacture," Weltwilrtschaftliches Archiv, 114, 275-295. 
Balassa, B. (1965), The Theory of Economic Integration, London: Allen \& Unwin.

Caves, R.E. (1981), "Intra-Industry Trade and Market Structure in the Industrial Countries," Oxford Economics Papers, 33, 203-223.

Deardorff, A.V. (1997), "Determinants of Bilateral Trade: Does Gravity Work in a Neoclassical World?," in J.Frankel (ed.), The Regionalization of the World Economy, Chicago: University of Chicago Press for NBER.

Dhar, S. and A. Panagariya (1996), "Is East Asia Less Open than North America and the EEC" Paper Presented at the International Economics Association Round-Table Conference in International Trade Policy and the Pacific Rim, Sydney, 15-17 July.

Drysdale, P. and R.G. Garnaut (1982), "Trade Intensities and the Analysis of Bilateral Trade Flows in a Many-Country World: A Survey," Hitotsubashi Journal of Economics, 22, 62-84.

Frankel, J.A. (1993), "Is Japan Creating a Yen Bloc in East Asia and the Pacific?," in J.A. Frankel and M. Kahler (eds.) Regionalism and Rivalry: Japan and the United States in Pacific Asia, Chicago: University of Chicago Press.

Frankel, J.A., E. Stein and S. Wei (1995), "Trading Blocs and the Americas: The Natural, the Unnatural and the Supernatural," Journal of Development Economics, 47, 61-95.

Fukasaku, K. (1992), Economic Regionalisation and Intra-Industry Trade:Pacific-Asian Perspectives, OECD Development Centre Technical Paper, No. 53.

Garnaut, R.G. (1972), Australian Trade with Southeast Asia: a Study of Resistances to Bilateral Trade Flows, PhD Dissertation, The Australian National University.

Geraci, V.J. and W. Prewo (1977), "Bilateral Trade Flows and Transport Costs," Review of Economics and Statistics, 59, 67-74.

Greenaway, D. and C.Milner (1981), “Trade Imbalance Effect and the Measurement of Intra-Industry Trade," Weltwirtschaftliches Archiv, 117, 756-762.

Griffiths, W.E. (1972), "Estimation of Actual Response Coefficients in the HildrethHouch Random Coefficient Model," Journal of the American Statistical Association, 67, 633-635.

Grubel, H. and P.J. Lloyd (1975), Intra-Industry Trade: The Theory and Measurement of International Trade in Differentiated Products, London: Macmillan.

Hildreth, C. and J. Houck (1968), "Some Estimators for a Model with Random Coefficients," Journal of American Statistical Association, 63, 584-595.

Kalirajan, Kaleeswaran. (1998). "Stochastic Varying Coefficients Gravity Model: An Application in Trade Analysis," Journal of Applied Statistics, 23, 275-287.

Krugman, P. (1981), "Intra-Industry Specialisation and the Gains from Trade," Journal of Political Economy, 89, 959-973.

Krugman, P. (1991), “The Move Toward Free Trade Zones," in Policy Implications of Trade and Currency Zones, Federal Reserve Bank of Kansas, Jackson Hole, Wyoming, August.

Linnemann, H. (1966), An Econometric Study of International Trade Flows, Amsterdam: North Holland Publishing Co.

Michaely, M. (1962), Concentration in International Trade, Contribution to Economic 
Analysis, 8, Amsterdam: North-Holland.

Panagariya, A. (1998), "Do Transport Costs Justify Regional Preferential Trading Arrangements?," Weltwirtschaftliches Archiv, 134, 280-301.

Shand, R.T. and K.P. Kalirajan (1997), "Yamazawa's Open Economic Association: An Indian Ocean Grouping for Economic Cooperation," The Developing Economies, 35, $3-25$.

Swamy, P.A.V.B. (1970), "Efficient Inference in Random Coefficient Regression Models," Econometrica, 38, 311-323.

Tharakan, P.K.M. (1984), "Intra-Industry Trade between the Industrial Countries and the Developing World," European Economic Review, 26, 213-227.

Tharakan, P.K.M. and J. Kol (1989), Intra-Industry Trade, Theory, Evidence and Extension, Hong Kong: Macmillan.

Tinbergen, J. (1962), Shaping the World Economy: Suggestions for an International Economic Policy, New York: The Twentieth Century Fund.

Vona, S. (1991), "On the Measurement of Intra-Industry Trade: Some Further Thoughts," Weltwirtschaftliches Archiv, 127, 678-700.

Yamazawa, I. (1970), "Intensity Analysis of World Trade Flow," Hitotsubashi Journal of Economics, 10, 61-90. 